\title{
LETTER
}

\section{Critical care ultrasound goal-directed versus early goal-directed therapy in septic shock}

\author{
Kun Yu' ${ }^{1}$, Shucheng Zhang ${ }^{1,2}$, Ni Chen ${ }^{1}$, Miao Chen ${ }^{1 *}$ and Wei Zhang ${ }^{1,3^{*}}$ (]) on behalf of the CCUGDT Study Group
}

() 2021 The Author(s)

\section{Dear Editor,}

Critical care ultrasound (CCUS) is widely accepted in the field of critical care medicine as a valuable tool in the intensive care unit and emergency department $[1,2]$. It plays a particularly pivotal role in the hemodynamic evaluation of septic shock. An analytical study on sepsis in the MIMIC-III database showed that CCUS can effectively reduce the 28-day mortality rate of critically ill patients with sepsis [3]. However, a randomized controlled trial suggested that ultrasound-guided fluid management (termed CCUS goal-directed therapy [CCUGDT]) did not improve the outcomes of patients with septic shock compared with early goal-directed therapy (EGDT) [4]. Our study was performed to compare the differences between CCUGDT and EGDT in patients with septic shock. The abstract of this study was submitted to LIVES Digital 2021 at the 34th Annual Congress of the European Society of Intensive Care Medicine on 3-6 October 2021 and accepted as an oral presentation by the Congress [5].

A pilot randomized controlled trial was performed to compare CCUGDT versus EGDT in patients with septic shock in a general intensive care unit of a tertiary care center from August 2018 to December 2019. The study was approved by the Ethics Committee of the

\footnotetext{
*Correspondence: chenmiao64@163.com; zhangwei_hxicu@163.com ${ }^{1}$ Department of Critical Care Medicine, Affiliated Hospital of Zunyi Medical University, 149 Dalian Road, Zunyi 563000, Guizhou, China Full author information is available at the end of the article

Kun Yu, Shucheng Zhang and Ni Chen have contributed equally to this work.
}

The members of CCUGDT Study Group are mentioned in the Acknowledgements section.
Affiliated Hospital of Zunyi Medical University, and written informed consent was obtained from each patient's family. This trial was retrospectively registered at clinicaltrials.gov (identifier ChiCTR1800020154). Block randomization was performed using Web-based software to assign 86 patients with septic shock to either the CCUGDT or EGDT group. relevant conventional monitoring indicators and ultrasound parameters were recorded at the time of enrollment $(0 \mathrm{~h})$ and at 6,12 , and $24 \mathrm{~h}$ in both groups. The primary clinical outcome was the lactate clearance rate (LCR) at $6 \mathrm{~h}$. The secondary endpoints were the volume administered and the fluid balance in the first $24 \mathrm{~h}$, the LCR at 12 and $24 \mathrm{~h}$, and 28-day mortality. The Chi-square test or Fisher's exact test was used to compare differences in proportions, and Student's $t$ test and the Mann-Whitney $U$ test for independent samples were used to compare means and medians, respectively. All statistical analyses were performed using two-tailed tests, and $P \leq 0.05$ was considered statistically significant.

A study flow chart is presented in Fig. 1. Eighty-six patients were randomly divided into the EGDT group $(n=44)$ and CCUGDT group $(n=42)$. There were no significant differences in baseline characteristics between the two groups (Supplementary Table 1). The 6-h LCR was significantly higher in the CCUGDT than EGDT group $(23.8 \%$ vs. $9.7 \%$, respectively; $P=0.010)$. The cumulative fluid infusion volume and fluid balance at 12 and $24 \mathrm{~h}$ were significantly lower in the CCUGDT than EGDT group $(P<0.05)$ (Supplementary Table 2$)$.

\section{实




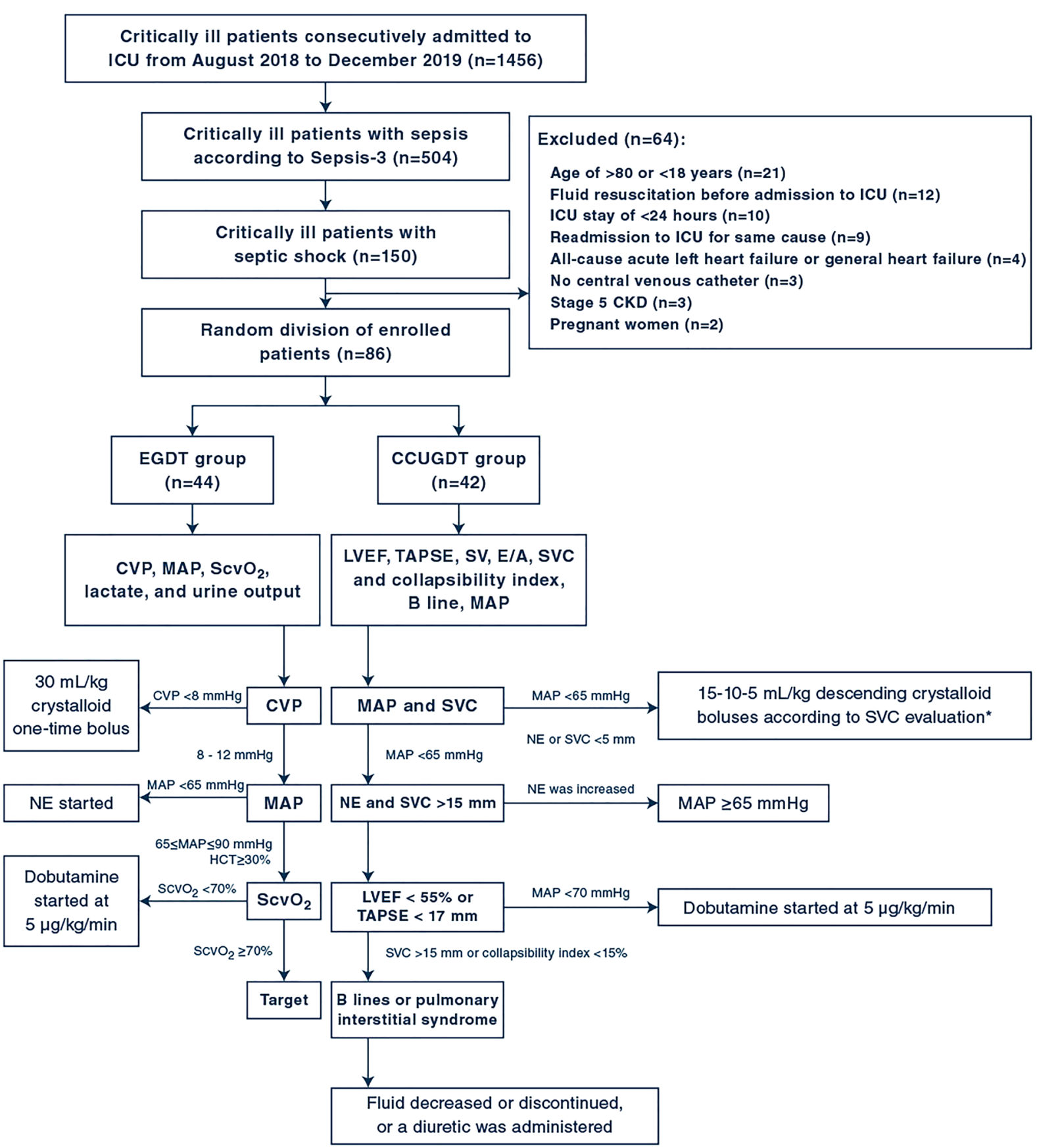

Fig. 1 Study flow chart. ICU intensive care unit, Sepsis-3 Third International Consensus Definitions for Sepsis and Septic Shock, CKD chronic kidney disease, EGDT early goal-directed therapy, CCUGDT critical care ultrasound goal-directed therapy, CVP central venous pressure, MAP mean arterial pressure, $\mathrm{SCVO}_{2}$ central venous oxygen saturation, LVEF left ventricular ejection fraction, TAPSE tricuspid annular plane systolic excursion, SV stroke volume, SVC superior vena cava, NE norepinephrine, HCT hematocrit. * To avoid excessive fluid infusion during fluid resuscitation we adopted a descending fluid infusion strategy: the first dose was given at $15 \mathrm{~mL} / \mathrm{kg}$ body weight the second dose was given at $10 \mathrm{~mL} / \mathrm{kg}$ body weight and the third dose was given at $5 \mathrm{~mL} / \mathrm{kg}$ body weight. Whether to give the next fluid infusion was dependent upon on the critical care ultrasound evaluation result after the last fluid infusion. 
This study showed that CCUGDT can effectively improve the 6-h LCR and reduce the 12- and 24-h cumulative fluid infusion volume compared with EGDT in patients with septic shock. Optimal fluid administration improves organ perfusion, but excess fluid resuscitation may lead to increased mortality. CCUGDT has developed rapidly, providing a promising new tool to monitor and guide hemodynamic management in septic shock.

\section{Supplementary Information}

The online version contains supplementary material available at https://doi. org/10.1007/s00134-021-06538-4.

\section{Author details \\ 1 Department of Critical Care Medicine, Affiliated Hospital of Zunyi Medical University, 149 Dalian Road, Zunyi 563000, Guizhou, China. ${ }^{2}$ Zunyi Medical University, Zunyi 563000, Guizhou, China. ${ }^{3}$ Department of Critical Care Medi- cine, Affiliated Mao-Tai Hospital of Zunyi Medical University, Renhuai 563000, Guizhou, China.}

\section{Acknowledgements}

We thank all the patients in this study and all members in the department of critical care medicine. We also thank Angela Morben, DVM, ELS, from Liwen Bianji (Edanz) (www.liwenbianji.cn/) for editing the English text of a draft of this manuscript. Those members of CCUGDT Study Group include Qiuyuan Xia, Qian Lei, Zirong Gao, Linlin Wu, Can Jin, and Bohan Li. Qiuyuan Xia (Hospital of Zunyi Medical University, 149 Dalian Road, Zunyi 563000, Guizhou, China, Qian Lei (Hospital of Zunyi Medical University, 149 Dalian Road, Zunyi 563000, Guizhou, China), Zirong Gao (Hospital of Zunyi Medical University, 149 Dalian Road, Zunyi 563000, Guizhou, China), Linlin Wu (Hospital of Zunyi Medical University, 149 Dalian Road, Zunyi 563000, Guizhou, China), Can Jin (Hospital of Zunyi Medical University, 149 Dalian Road, Zunyi 563000, Guizhou, China). Bohan Li (Hospital of Zunyi Medical University, 149 Dalian Road, Zunyi 563000, Guizhou, China).

\section{Author contributions}

WZ had full access to all data in the present study and accepts responsibility for data management and accuracy of the data analyses. Study concept and design: WZ and MC. Acquisition and interpretation of data: KY, NC, LLW, $\mathrm{CJ}$, and QYX. Drafting of the manuscript: $\mathrm{KY}, \mathrm{SCZ}, \mathrm{CJ}$, and WZ. Critical revision of the manuscript for important intellectual content: WZ, SCZ, CJ, and MC. Administrative, technical, or material support: NC, ZRG, QYX, BHL, SCZ, QL, and KY. Study supervision: WZ and MC. All authors agree to the submission of the final version of this manuscript. WZ is the study guarantor.

\section{Funding}

This study was supported by the Growth Project of Young Scientific and Technological Talents of Guizhou Provincial Department of Education (CJ-981), the Science and Technology Support Plan of Guizhou Province in 2019 (Qian Ke He Support [2019] 2834), and the Science and Technology Plan of Guizhou Province in 2020 (Foundation of Guizhou Science and Technology Cooperation [2020]1Z061).

\section{Data availability}

We stated that all the data and materials were true and available in the study.

\section{Declarations}

\section{Conflicts of interest}

All authors declare that there are no conflicts of interest involved in the article.

\section{Ethical approval and consent to participate}

Ethics approval in the study was approved by the Biomedical Ethics Committee of Affiliated Hospital of Zunyi Medical University and written consent was obtained from the patients or their relatives.

\section{Consent for publication}

All authors have read and approved the manuscript version, and agree to submit for consideration for publication in the journal. We confirm that we have read the Journal's position on issues involved in ethical publication and affirm that this report is consistent with those guidelines.

\section{Open Access}

This article is licensed under a Creative Commons Attribution-NonCommercial 4.0 International License, which permits any non-commercial use, sharing, adaptation, distribution and reproduction in any medium or format, as long as you give appropriate credit to the original author(s) and the source, provide a link to the Creative Commons licence, and indicate if changes were made. The images or other third party material in this article are included in the article's Creative Commons licence, unless indicated otherwise in a credit line to the material. If material is not included in the article's Creative Commons licence and your intended use is not permitted by statutory regulation or exceeds the permitted use, you will need to obtain permission directly from the copyright holder. To view a copy of this licence, visit http://creativecommons.org/licen ses/by-nc/4.0/.

\section{Publisher's Note}

Springer Nature remains neutral with regard to jurisdictional claims in published maps and institutional affiliations.

\section{Accepted: 15 September 2021}

Published online: 7 October 2021

\section{References}

1. Vieillard-Baron A, Millington SJ, Sanfilippo F, Chew M, Diaz-Gomez J, McLean A, Pinsky MR, Pulido J, Mayo P, Fletcher N (2019) A decade of progress in critical care echocardiography: a narrative review. Intensive Care Med 45:770-788

2. Schnittke N, Schmidt J, Barvalia U, Emmerich K, Kory P, Damewood S (2020) Assessment of dynamic changes in cardiac function during resuscitation of patients with suspected septic shock: a prospective, observational, cohort study. Am J Emerg Med 38:2653-2657

3. Feng M, McSparron Jl, Kien DT, Stone DJ, Roberts DH, Schwartzstein RM, Vieillard-Baron A, Celi LA (2018) Transthoracic echocardiography and mortality in sepsis: analysis of the MIMIC-III database. Intensive Care Med 44:884-892

4. Lanspa MJ, Burk RE, Wilson EL, Hirshberg EL, Grissom CK, Brown SM (2018) Echocardiogram-guided resuscitation versus early goal-directed therapy in the treatment of septic shock: a randomized, controlled, feasibility trial. J Intensive Care 6:50

5. Zhang W (2021) Critical care ultrasound goal-directed versus early goaldirected therapy in septic shock: a randomized controlled study. https:// doi.org/10.1186/s40635-021-00413-8 